\title{
EXPECTANT MANAGEMENT VS ACTIVE MANAGEMENT OF PREMATURE MEMBRANE RUPTURE: A retrospective cohort study
}

\author{
Amanda Jácome Espinoza ${ }^{1}$, Luis Hidalgo Yánez ${ }^{1}$, María Carrasco Guerra ${ }^{2}$, and Lautaro \\ Chávez Iza ${ }^{1}$ \\ ${ }^{1}$ Hospital Carlos Andrade Marin \\ ${ }^{2}$ Pontificia Universidad Catolica del Ecuador
}

October 1, 2020

\begin{abstract}
Objective: To evaluate the expectant management (EM) versus active management (AM) of PROM (Premature Rupture of Membranes) in pregnancies more than 34 weeks of gestation as a factor associated with a decrease of neonatal complications because of prematurity. Design: A retrospective cohort study. Setting: Pregnancy women with 34-36.6 weeks of gestation with PROM attended in Carlos Andrade Marín Specialty Hospital, Quito-Ecuador; in the years 2016 and July 2019. Population: 209 patients: this sample was separately in two groups by inclusion and exclusion criteria; 103 cases were management expectantly and 106 cases were management actively. Methods: The risk was estimated calculation relative risk (RR) and Chi-square with p-value less than 0.05, 95\% CI. Main Outcome Measures: frequency of neonatal complications in both groups. Results: The prevalence of PROM was $1.95 \%$, associated with preterm delivery in $13.59 \%$. Caesarean delivery was $25.2 \%$ (EM) and $50.9 \%$ (AM) with $\mathrm{p}<0.05$. There were no significant differences in variables: maternal infection RR: 1,324 (95\% CI: 0.972-1.885) in EM and AM: RR: 0.683 (95\% CI: 0.398-1.172); neonatal sepsis RR: 0.909 (95\% CI: 0.608-1359) in EM, and RR: 1.091 (95\% CI: 0.773-1540) in AM; respiratory distress syndrome RR: 0.993 (expectant) and RR: 1.01 (active), and prolonged hospitalization. The risk of neonatal mortality and necrotizing enterocolitis is higher in newborns of mothers under AM, with RR: 2,013 (95\% CI: 1,723-2351). Conclusions: There were no significant differences between both groups, but there was a significant increase in neonatal mortality, necrotizing enterocolitis, and caesarean after active management.
\end{abstract}

\section{EXPECTANT MANAGEMENT VERSUS ACTIVE MANAGEMENT OF PREMATURE MEMBRANE RUPTURE: A retrospective cohort study}

\section{Amanda Angélica Jácome Espinoza ${ }^{1}$, Luis Ramiro Hidalgo Yánez ${ }^{2}$, María Lucila Carrasco Guerra $^{3}$, Lautaro Santiago Chávez Iza ${ }^{2}$.}

${ }^{1}$ Medical Specialty in Obstetrics and Gynaecology, Pontifical Catholic University of Quito, Quito - Ecuador.

2 Attending physician of the HECAM Obstetrics and Gynaecology service / Professor of the PUCE School of Medicine, Quito - Ecuador.

${ }^{3}$ Clinical-Health Pathologist / Teacher, School of Medicine PUCE, Quito - Ecuador.

Correspondence information:

Author's name. Amanda Angélica Jácome Espinoza.

Address. Luis A. Guerra y 10 de Agosto, Puyo - Ecuador, Postal Code: 160150. 
E-mail.angeajes@hotmail.es

Phone number. $(+593) 995600441$

As mentioned article: Jácome A, Hidalgo R, Carrasco L, Chavez S. Expectant management vs active management of premature membrane breakage: A retrospective cohort study. Quito- Ecuador, 2020.

\section{ABSTRACT}

Objective: To evaluate the expectant management (EM) versus active management (AM) of PROM (Premature Rupture of Membranes) in pregnancies more than 34 weeks of gestation as a factor associated with a decrease of neonatal complications because of prematurity.Design: A retrospective cohort study. Setting:Pregnancy women with 34-36.6 weeks of gestation with PROM attended in Carlos Andrade Marin Specialty Hospital, Quito-Ecuador; in the years 2016 and July 2019. Population: 209 patients: this sample was separately in two groups by inclusion and exclusion criteria; 103 cases were management expectantly and 106 cases were management actively.Methods: The risk was estimated calculation relative risk (RR) and Chi-square with p-value less than 0.05, 95\% CI. Main Outcome Measures: frequency of neonatal complications in both groups.Results: The prevalence of PROM was $1.95 \%$, associated with preterm delivery in $13.59 \%$. Caesarean delivery was $25.2 \%(\mathrm{EM})$ and $50.9 \%(\mathrm{AM})$ with $\mathrm{p}<0.05$. There were no significant differences in variables: maternal infection RR: 1,324 (95\% CI: 0.972-1.885) in EM and AM: RR: 0.683 (95\% CI: 0.398-1.172); neonatal sepsis RR: 0.909 (95\% CI: 0.608-1359) in EM, and RR: 1.091 (95\% CI: 0.773-1540) in AM; respiratory distress syndrome RR: 0.993 (expectant) and RR: 1.01 (active), and prolonged hospitalization. The risk of neonatal mortality and necrotizing enterocolitis is higher in newborns of mothers under AM, with RR: 2,013 (95\% CI: 1,723-2351).Conclusions: There were no significant differences between both groups, but there was a significant increase in neonatal mortality, necrotizing enterocolitis, and caesarean after active management.

Key words: premature rupture of membranes, expectant management, active management, neonatal complications.

\section{Funding Statement}

We worked with help of "Fondo Publicalo" by Pontifical Catholic University of Quito resources.

\section{Introduction}

Premature rupture of membranes is losing the integrity of chorioamniotic membranes, which occurs from 20 weeks of gestation until before the onset of labor ${ }^{1}$, it happens with a frequency of 2 to $3 \%$ before 37 weeks $^{2}$ and is associated with 30 to $49 \%$ of preterm pregnancies ${ }^{3}$.

Latency period refers to the time elapsed since the rupture of membranes occurs until delivery occurs; and gestational age will determine the prognosis, ideal treatment, and the way to end pregnancy ${ }^{1}$.

It is possible that rupture of membranes in preterm pregnancies originates activation of apoptosis mechanisms, mechanical forces, or by the action of catabolic enzymes such as collagenase linked to both inflammatory and infectious responses ${ }^{4,5}$. Although etiology is different, triggering is likely that all processes interact with each other, reaching a common pathway that is membrane rupture ${ }^{6}$.

An inflammatory response caused by maternal infection, whether systemic or localized, has as a possible component, activation of cytokines such as interleukin $1 \beta$ and TNF- $\alpha^{7}$. Cytokines, also called interleukins (IL), are soluble mediators that allow interactions between cells of the immune system ${ }^{8}$. Cytokines' functions are stimulating prostaglandin synthesis and metalloproteinases production by extracellular matrix. One of these is IL-8, which causes weakness of the chorioamniotic membranes and the softening of the cervix ${ }^{9}$. Cytokines also promote the apoptosis of amniocytes and activation of complement leading to endothelial damage with increased permeability, impaired fetal placental perfusion, and myometrial contractions that lead to rupture of membranes ${ }^{10}$. 
It is possible that there is a sterile inflammatory response, which stimulates the production of cytokine receptors identical to those that would be generated secondary to an infection, but they surely follow different processes $^{9}$. In a study by Romero et al. $(2014)^{11}$ found that sterile intraamniotic inflammation occurred in $29 \%$ of patients with premature rupture of membranes and was more common the earlier pregnancy.

Intraamniotic infection is the main cause of preterm delivery, one of the main problems in obstetrics ${ }^{10}$. intraamniotic infection demonstrated by amniotic fluid study after amniocentesis shows that microbial invasion into the amniotic cavity is present in 10 to $15 \%{ }^{12}$; other authors say $20 \% 13$ of the patients with preterm delivery and integral membranes, reaching $25 \%$ when cause labor ${ }^{11}$, and 30 to $50 \%$ of patients with preterm delivery and premature rupture of membranes ${ }^{12,14}$.

For identification of both maternal and neonatal infection secondary to ruptured membranes, the quantification of interleukin 6 levels may be chosen. Reference values in maternal blood range from 0.2 to $7.8 \mathrm{pg} / \mathrm{ml}{ }^{15}$. In neonates, this cytokine is a good predictor of early sepsis with a cut-off point of $40 \mathrm{pg} / \mathrm{ml}$ with a positive predictive value of $100 \%$ when is used in combination with another marker such as C-reactive protein (CRP) as long as it is positive ${ }^{16}$. Other markers, such as leucocytes, neutrophils, and procalcitonin, are also used such as diagnostic criteria, reference ranges may vary according to the laboratory performs the analysis.

Complications secondary to this pathology increase the risk of morbidity and mortality for both mother and neonate, among the most important are: intraamniotic infection, premature placental abruption, cord prolapse, maternal sepsis, neonatal respiratory distress, neonatal sepsis, enterocolitis necrotizing, neurodevelopmental impairment, etc ${ }^{17}$.

Management of preterm rupture of membranes varies according to gestational age; it is a controversial issue in pregnancies of 34 to 36.6 weeks, when the fetus is considered relatively mature, without being exempt from complications typical of prematurity, therefore that benefits in the fetus when continuing the gestation after the PROM (Premature Rupture of Membranes) can be considerable. Optimal expectant management aims to maximize the benefits of fetal lung maturity after the administration of corticosteroids, allow an increase in fetal weight by continuing the waiting time, and avoid potential damage to the mother-child binomial.

Corticosteroid and antibiotic therapy are part of expectant management of preterm rupture of membranes, which includes observation of the mother while awaiting the start of labor spontaneously in absence of complications that increase needs for immediate preterm delivery. The primary objective is getting as close to term as possible. Recognition of maternal and fetal complications is imperative in terms of being able to adequately manage them during expectant management.

The potential risk of iatrogenic prematurity associated with ending a pregnancy so early and unplanned pregnancies with PROM is significant. It includes complications typical of prematurity, mainly respiratory distress, neurodevelopmental deficits, difficulty in feeding and thermoregulation, and a prolonged neonatal hospitalization that will depend on the gestational age at which delivery occurs.

The study by Lewis 1996 concludes that complications of prematurity are significantly reduced when delivery occurs after 34 weeks of gestation compared to those born before 34 weeks; however, are considered that preterm newborns between 34 and 37 weeks still physiologically immature, so their morbidity and mortality is significantly increased compared to those born at term ${ }^{18,19}$.

Therefore, evaluation of perinatal results in the study of patients with ruptured membranes from 34 to 36.6 weeks managed expectantly could be an alternative in the reduction of neonatal complications related to prematurity compared to active management.

\section{Materials and methods}

A retrospective cohort that included 209 patients from 34 to 36.6 weeks of gestation with a history of premature rupture of membranes, from Carlos Andrade Marin Hospital in Quito between years 2016 to July 2019. The sample was separated according to inclusion criteria for each group, in exposed and unexposed; 103 cases were found in expectant management and 106 cases in active management. 
Definition of groups:

* Group of exposed (expectant management)

It refers to all patients with a pregnancy between 34 to 36.6 weeks with rupture of membranes, regardless of maternal age, in which termination of pregnancy occurs after spontaneous onset (without administration of medication or extrinsic mechanisms) of uterine contractions; regardless of the administration of antibiotic therapy or pulmonary maturation with corticosteroids.

Inclusion criteria: Patients treated at the Carlos Andrade Marín Hospital between 2016 and July 2019; with spontaneous onset of labor, regardless of latency time of ruptured membranes, fetal presentation, or whether or not a previous caesarean section had. Patients who had ruptured membranes greater than 26 weeks, but delivery had not yet occurred at 34 weeks. Patients for whom induction of labor was indicated at 37 weeks with a history of ruptured membranes up to 36.6 weeks after being managed expectantly.

Group of not exposed (active management)

It refers to all patients with a pregnancy of 34 to 36.6 weeks with ruptured membranes, regardless of maternal age, in which the termination of pregnancy occurs after administration of medication ( misoprostol, oxytocin ) or extrinsic mechanisms (traction tube) that cause the onset of uterine contractions or indication of termination of pregnancy by caesarean section, immediately after hospital admission. Regardless if we're administrated antibiotic therapy or pulmonary maturation with corticosteroids.

Inclusion criteria: Patients treated at the Carlos Andrade Marín Hospital between 2016 and July 2019; patients who were inducing labor (administered misoprostol, oxytocin) immediately after to hospital admission; performing caesarean section without spontaneous uterine activity.

Exclusion criteria for both groups: Criteria for clinical chorioamnionitis on admission to hospital; fetal anomalies; stillbirth; patients with vertically transmitted diseases such as HIV - VHS; n preterm infants referred from other nursing homes.

The data were subjected to tabulations in explanatory tables using Microsoft Word and Microsoft Excel programs. Data were exported to the SPSS version 24.0 program for analysis. For descriptive variables, percentages, average, and means will be calculated.

For associating variables such as the risk of complications and the type of therapeutic management, contingency tables were used; the dependence between the variables was determined by means of Chi-square. The level of association between the variables was measured by calculating RR and Chi-square to compare qualitative variables, with a statistically significant $\mathrm{p}<0.05$ and a confidence interval of $95 \%$.

\section{Results}

Of 12036 deliveries attended from 2016 to July 2019 at the Carlos Andrade Marín Hospital, 2683 were preterm, this represents 22.41\%; 1728 deliveries occurred between 34 and 36.6 weeks, which represents $64.40 \%$ of this group, the cases of deliveries with ruptured membranes between 34 and 36.6 weeks was 235 ( $1.95 \%$ of all births and $13.59 \%$ of the preterm group).

209 patients met inclusion criteria: 103 for expectant management and 106 for active management. 26 patients were excluded: most cases (20 patients - 8.5\%) had congenital fetal malformations, $4(1.70 \%)$ were excluded due to lack of data, 1 case was admitted with signs of chorioamnionitis and another with a diagnosis of stillbirth $(0.42 \%)$ each case).

Table 1 describes the clinical characteristics of patients who were attended between January 2016 and July 2019 , due to premature rupture of the membranes. In all cases, the ruptured membranes occurred after 34 weeks of gestation.

Active management was more frequent in $73.5 \%$ of patients with the evolution of fewer than 24 hours, while in conservative management, delivery occurred spontaneously in $55.4 \%$ within the first 24 hours of admission; 
in patients with a latency of 2 to 6 days the frequency was $22.3 \%$, and $11.7 \%$ of patients break greater than 7 days.

Regarding the use of corticosteroids for lung maturation, it was similar in both groups: $58.3 \%$ of expectant management versus $48.1 \%$ of patients with active management.

There were no signs of intrauterine infection in any of the groups, however, when taking into account of inflammatory values and hematological biomarkers (leucocytes over 15,000 cells $/ \mathrm{mm}^{3}$ and Interleukin-6, greater than $14 \mathrm{pg} / \mathrm{mL}$ ), it was established that, $8.5 \%$ of patients who were actively managed and $15.5 \%$ of patients managed expectantly presented elevation of these markers.

Regarding the administration of antibiotics at hospital admission, in the group of patients managed actively it was $75.5 \%$, while in the group of patients managed expectantly it was $70.9 \%$ without there being a significant difference between both groups.

There were significant differences in the frequency of caesarean delivery between groups. Patients who were managed expectantly had a caesarean delivery frequency of $25.2 \%$, compared to patients who were actively managed, whose caesarean delivery frequency was $50.9 \%$, RR: 3.075 (95\% CI: 1.713-5,522).

The main reasons for implementation caesarean, in both expectant management group as in the active management group was: a history of caesarean section (30.2\% and $42.3 \%$ of patients respectively), breech presentation (34\% and $19.2 \%$ respectively), amniotic fluid alterations (3.8\% and $15.4 \%$ respectively) and compromise of fetal well-being ( $15.1 \%$ and $7.7 \%$ respectively). Among all the causes that indicated caesarean section, there were no statistically significant differences between both groups.

In all cases, a leucocyte count with a differential formula was performed, as part of the evaluative process; in addition, the biomarkers were quantified: procalcitonin, C-reactive protein, and interleukin 6 .

Table 2 shows the means obtained in hematological parameters and in inflammatory biomarkers, which suggest the presence or not of infection (leucocytes more than 15,000 cells $/ \mathrm{mm}^{3}$ and Interleukin- 6 more than $14 \mathrm{pg} / \mathrm{mL}$ ). Significant differences were found in each of the tests applied to patients. The mean leucocytes in patients with infection were 14,310 cells $/ \mathrm{mm}^{3}$ versus 9,230 cells $/ \mathrm{mm}^{3}$, established in patients without any infection/inflammation. In the case of the neutrophil difference, a mean of $75.55 \%$ was calculated in patients with infection and $70.21 \%$ in patients without infection.

The behavior of inflammatory biomarkers was notable among patients with infection. For procalcitonin, a mean of $0.48 \mathrm{ng} / \mathrm{mL}$ was obtained in patients with infection and $0.07 \mathrm{pg} / \mathrm{mL}$ in patients without infection. For C-reactive protein, the mean in patients with infection was $1.47 \mathrm{mg} / \mathrm{dL}$ and $0.91 \mathrm{mg} / \mathrm{dL}$ in patients without this condition, in the same way, an important difference was founded in the quantification of interleukin- 6 in patients with infection, whose mean was $29.53 \mathrm{pg} / \mathrm{mL}$ in relation to $5.66 \mathrm{pg} / \mathrm{mL}$ in patients without infection.

Table 3 shows the clinical characteristics of the newborns of mothers who were actively and expectantly treated for premature rupture of the membranes. In each treatment group, there were no significant differences in relation to sex, weight, or Apgar score of newborns.

Regarding the length of hospitalization, there were no differences between the newborns of mothers who were treated actively or conservatively, although, a higher frequency of prolonged hospitalizations (more than 48 hours) was evidenced in the group of infants born to mothers under active treatment. 47 patients were referred to other health units (24 in a group of newborns of mothers under expectant treatment and 23 in the group of newborns of mothers under active treatment).

The most common causes of prolonged hospitalization were rum: the study of infection in $39.7 \%$ in patients with expectant management and respiratory distress syndrome in $34.8 \%$ of patients with active management, a similar proportion was found in terms of the study of infection and hyperbilirubinemia of $25 \%$ for each cause, with no statistically significant difference between the two groups. 
Table 4 describes the complications presented in neonates of mothers with premature rupture of the membranes according to the treatment received. Regarding infectious complications, there were no significant differences between each of the groups, however, a greater number of newborns with clinical signs of infection $(\mathrm{n}=6)$ were detected in the group with a history of active treatment, compared to newborns with a history of expectant treatment $(\mathrm{n}=3)$.

37 blood cultures were performed in neonates of mothers who received expectant treatment and 34 in neonates of mothers who received active treatment, which two were positive in the expectant treatment group and one in active treatment group.

According to this, $29.2 \%$ of neonates undergoing active treatment received an incomplete antibiotic regimen and $31.1 \%$ in the expectant treatment group. Such discontinuation of therapy was due to initial suspicion of infection but with the subsequent confirmation of biomarkers within normal parameters. The majority of neonates (58.3\% in the expectant treatment group and $64.2 \%$ in the active group) did not receive any antibiotic treatment, and only $10.7 \%$ in the expectant treatment group and $6.6 \%$ in the active treatment group received full antibiotic treatment.

Regarding syndrome cases distress respiratory, 22 described cases (20.8\%) in the group of infants of mothers with active treatment, and 19 cases $(18.4 \%)$ in the expectant management group, however, no significant differences between each modality of oxygen therapy and ventilatory support.

In other complications, there was a low prevalence of necrotizing enterocolitis, finding 1 case in the expectant treatment group and 2 cases in the active management group, however, these differences are not statistically significant.

The survival rate was higher than $98 \%$ in both groups, however, one case of neonatal death was detected in the group of neonates of mothers with active treatment.

Table 5 shows the relationship between gestational age and the presence of neonatal complications. There were no significant differences in the frequency of neonatal infection between each of the gestational age groups. Nor was there any evidence of a difference in the frequency of diagnosis of necrotizing enterocolitis.

In the case of respiratory distress syndrome, there was a greater need for ventilatory support in newborns aged 34-35 weeks (35.9\%), compared to newborns aged 35.1-36 weeks (21.2\%) and older than 36 weeks $(7.5 \%)$, therefore, there is a significant difference in the appearance of this complication depending on the gestational age.

Regarding the frequency of prolonged hospitalization, it was significantly higher in newborns with a gestational age of 34-35 weeks (76.5\%) and 35.1-36 weeks (67.3\%), compared to neonates older than 36 weeks $(\mathrm{p}=0.001)$. There were no significant differences between prolonged hospitalization causes; however, there was a greater frequency of stay greater than 48 hours, in neonates of 34 and 35 weeks due to respiratory distress syndrome $(38.72 \%)$.

According to the differences found in the prevalence of respiratory distress syndrome, Table 6 describes the relationship between a history of lung maturation and the appearance of this complication in newborns of mothers with premature rupture of membranes.

In-group of neonates of mothers with expectant management, newborns who did not receive lung maturation had a higher frequency of respiratory distress syndrome, compared to newborns who received said treatment ( $35 \%$ versus $9.3 \%, \mathrm{p}=0.003)$. Similarly, it happens in newborns of mothers with active management $(32.7 \%$ in those who received lung maturation and $15.7 \%$ in newborns who did not receive lung maturation, $\mathrm{p}=0.042)$.

Regarding ventilatory support, a greater need for CPAP use as evidenced in newborns without previous lung maturation ( $25 \%$ in the group of newborns of mothers with expectant management and $18.2 \%$ in newborns of mothers with active management). 
Table 7 shows an analysis of risk related to maternal and neonatal complications, depending on the type of management applied in mothers with premature rupture of membranes.

In women who received expectant management, an increased risk of maternal infection was evidenced with a RR: 1,324 (95\% CI: 0.972-1.885), while active management seems to be a protective factor against this event, with a RR: 0.683 (95\% CI: 0.398-1.172).

The risk of neonatal sepsis did not show significant differences, depending on the type of management, in the case of newborns of mothers under expectant management, a RR: 0.909 (95\% CI: 0.608-1.359) is described, while, in those born of mothers under active management, have a RR: 1.091 (95\% CI: 0.773-1.540). Nor were there any differences in terms of management and presence of respiratory distress syndrome RR: 0.993 and RR: 1.01, respectively.

Risk of neonatal mortality and necrotizing enterocolitis is higher in newborns of mothers under active management, with RR: 2,013 (95\% CI: 1,723-2,351) and RR: 1,321 (95\% CI: 0.587-2,973) respectively.

\section{Discussion}

Premature rupture of membranes in pregnancies from 34 to 36.6 weeks, represented $1.94 \%$ of all births, a frequency similar to that reported by Schmitz et al. $(2019)^{2}$. It was associated with preterm birth in $13.54 \%$, which is consistent with what Mercer $(2015)^{3}$ and Van der Heyden $(2014)^{20}$ report in their studies. Latency time in expectant management reached more than 7 days in $11.3 \%$, from 2 to 6 days in $22.3 \%$, while in most cases it occurred within the first 24 hours by $55.4 \%$. These findings coincide with the results of Sae-Lin, and Wanitpongpan $(2018)^{21}$ in which report the average latency period was 2 days with a mean gestational age of 35 weeks. The use of corticosteroids was similar to an average of $53.2 \%$ in each type of management; this is because during this period their administration in pregnancies greater than 34 weeks was under debate, so their prescription was a medical consideration. Now the recommendation they make in the study by Gyamfi et al. $(2016)^{22}$ and ACOG $(2018)^{23}$ of a single dose of corticosteroid between 34 and 36.6 days of gestational age, if they had not previously received them. Maternal inflammatory markers elevation occurred in $15.5 \%$ of expectant management, in relation to $8.5 \%$ of active management. However, no signs of infection were clinically expressed, which may have been favored by the prophylactic use of antibiotics such as it is reported by Bond et al. (2017 $)^{24}$ in which they find that the prophylactic use of antibiotics is effective in reducing maternal infection. The differences found in evaluating the leucocyte formula were statistically significant between the two groups, finding the highest values in the expectant group; it is explained by the longer duration of the latency period and longer exposure to uterine activity (regular or irregular) in expectant management ${ }^{25}$. When evaluating the positive maternal biomarkers, it was determined that the mean for leucocytes was 14,310 cells $/ \mathrm{mm}^{3}$, neutrophils of $75.5 \%$, procalcitonin of $0.48 \mathrm{ng} / \mathrm{ml}$, and CRP of $1.47 \mathrm{mg} / \mathrm{dl}$ with statistically significant differences in comparison with maternal biomarkers in a normal range. According to the compartmental theory in the study carried out by Dulay et al. $(2015)^{26}$ found no relationship between histological chorioamnionitis and serum IL-6, CRP, or procalcitonin values and none exceeded the predictive value of leukocytosis. According to Popowski et al. $(2011)^{27}$ leucocytosis has a higher specificity $(95 \%)$ the higher its serum levels are: $16-20,000$ cells $/ \mathrm{mm}^{3}$. Therefore, these markers by themselves do not play a preponderant role in the prognosis and determination of intraamniotic infection. The majority of patients received antibiotic prophylaxis before delivery in both groups with a frequency of 78.3 for expectant management and $70.9 \%$ for active management, which is the recommendation in these patients according to CONGOF $(2019)^{2}$, FASGO $(2018)^{28}$, AGOG $(2018)^{23}$, RCGO (2018) ${ }^{29}$, among others. We found statistically significant differences in the frequency of caesarean delivery in actively managed patients in $50.9 \%$ versus $25.2 \%$ under expectant management. Previous caesarean section and breech presentation being the most frequent causes in both groups; which is related to the results found by Bond et al. $(2017)^{24}$ and Quist et al. $(2018)^{30}$ in which the frequency of caesarean sections was higher in the active management group. No significant differences were found regarding the sex, weight, and Apgar of the newborns in both groups, which gives homogeneity of the population. Prolonged hospitalization time (greater than 48 hours) 
was more frequent in infants of actively treated mothers, however, these differences were not statistically significant. In correlation with the study by Morris et al. $(2016)^{31}$ where a significant increase in the stay in the intensive care unit was determined in neonates in the active management group, as a consequence of low birth weight, increased risk of respiratory distress syndrome (RR 1.6, 95\% CI 1.1-2.3) and mechanical ventilation (RR 1.4, 95\% CI 1.0-1.8). Regarding infectious complications, no significant differences were

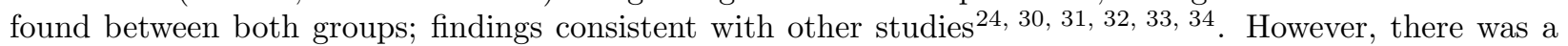
higher frequency of clinical signs of sepsis in neonates after active management, as well as the elevation of inflammatory/infectious markers, without finding any cause other than prematurity. The administration of antibiotics in neonates was not necessary for $58.3 \%$ with a history of expectant management and in $64.2 \%$ of active management, and only $10.7 \%$ after expectant management of a complete antibiotic scheme, without this being statistically significant Regarding the occurrence of respiratory distress syndrome and the use of oxygen supplementation or ventilatory support, there was no statistical difference in both cases (expectant management-RR: 0.993 and active management-RR: 1.01), however in one case there was it required the use of invasive mechanical ventilation by the hyaline membrane, after active management. Statistically significant differences were found regarding the occurrence of respiratory distress syndrome and lower gestational age, $35.9 \%$ between 34 and 35 weeks, and $7.5 \%$ after 36 weeks, as well as in newborns who did not receive lung maturation previously. These findings are in accordance with the meta-analysis 35 where they found that the incidence of severe respiratory distress syndrome was significantly reduced. However, repeated doses are not recommended ${ }^{36}$. Necrotizing enterocolitis was not prevalent, this may be due to the fact that it is dependent on gestational age (less than 32 weeks) and birth weight (less than 1500gr). However, it occurred in one case after expectant management and two cases in the group of active management. Neonatal death occurred in the active management group, with a single risk factor that is prematurity (values of normal biomarkers in the mother-child binomial. neonatal weight was $1830 \mathrm{gr}$, received antibiotic prophylaxis, and lung maturation), confirming its high index of mortality that consider it between 20 and $50 \%{ }^{37}$. In women who received expectant management, an increased risk of maternal infection was evidenced with a RR: 1,324 (95\% CI: 0.972-1.885), while active management seems to be a protective factor against this event, with a RR: 0.683 (95\% CI: 0.398-1.172); determined according to the elevation of biomarkers above the reference values. However, to determine its impact, studies have been carried out in search of histological chorioamnionitis at the placental level. Seong et al. $(2008)^{25}$ found that in placentas from term pregnancies, labor produced histological chorioamnionitis without increased inflammation at the level of fetal tissue with a prevalence of $19 \%$. According to Rodriguez et al. $(2016)^{38}$, histological sensitivity of placentas study from patients with clinical chorioamnionitis and ruptured membranes was $81 \%$ for predicting neonatal sepsis, however, $49 \%$ of newborns with sepsis had a histological study of their normal placentas. Neonatal sepsis risk did not show significant differences, between management. In the case of newborns of mothers under expectant management RR: 0.909 (95\% CI: 0.608-1.359) is described, while, in those born of mothers under active management have RR: 1,091 (95\% CI: 0.773-1.540), this despite the fact that higher levels of biomarkers were found in mothers with expectant management. What is correlated to studies such as that of Gisslen et al. $(2016)^{39}$ in which it was determined that in moderate and late preterm infants, despite fetal exposure to funisitis and increased cytokines in umbilical cord blood, neonatal morbidity did not increase. The neonatal survival rate was greater than $98 \%$ in both groups. Neonatal mortality risk for necrotizing enterocolitis is higher in newborns of mothers undergoing active management, with RR: 2,013 (95\% CI: 1,723-2,351) and RR: 1,321 (95\% CI: 0.587-2,973) respectively, findings consistent with Bond et al. $(2017)^{24}$ that found an increase in neonatal mortality risk (RR $2.55,95 \%$ CI 1.17-5.56) in the active management group.4.1. Study limitations

Although the estimated sample number was reached, it was not possible to do a long-term follow-up of infants who were transferred due to the inability to access that information.

\section{Conclusions}

- In the present study, it was possible to evaluate expectant management versus active management of premature rupture of membranes and it was determined that degree of neonatal complications will depend on the gestational age at which delivery occurs, with slight differences but not statistically significant between 
both groups. - A neonatal survival rate greater than $98 \%$ was identified for both groups, with a higher risk of mortality and necrotizing enterocolitis in the active management group. - Neonatal sepsis risk did not show significant differences, depending on the type of management. - Necrotizing enterocolitis was not very prevalent; however, it occurred in one case after expectant management and two cases in the active management group, being the reason for neonatal death in this group. - Frequency of respiratory distress syndrome was similar in both groups, however, there was a statistical difference with a tendency to be more frequent in neonates who did not receive lung maturation and between 34 and 35 weeks of gestation in $35.9 \%$ in relation to age gestational age greater than 36 weeks. - Prevalence of caesarean section was higher in cases of active management with 50.9\%. - Hospitalization prolonged (greater than 48 hours) was more common in infants of mothers treated actively, more often associated with respiratory distress syndrome, however, this result was not statistically significant. - Maternal infection considering positive inflammatory and infectious markers did not increase the risk of neonatal sepsis, there were no clinical manifestations of chorioamnionitis in either of the two groups.

\section{Abbreviations:}

PROM Premature Rupture of Membranes

HECAM Hospital de Especialidades Carlos Andrade Marin

PUCE Pontificia Universidad Catolica del Ecuador

WHO World Health Organization

ACOG American College of Obstetricians and Gynecologists

IL Interleukin

TNF - $\alpha$ Tumor Necrosis Factor Alpha

CONGOF French College of Gynaecologists and Obstetricians

FASGO Federación Argentina de Sociedades de Ginecología y Obstetricia

CRP C-reactive protein

\section{Disclosure of interest}

The authors declare no have financial, personal, political, intellectual or religious interests.

\section{Contribution to authorship}

AJ: With conception, design work, planning, recollection data. AJ and LC: getting results. AJ, RH, and LC: carrying out, analysing, interpretation of data, and writing up of the work. RH, LC and SC: Critical revision of the work. Approval of its final version: All authors read and approved the final version of the article.

\section{Author information}

Amanda Angélica Jácome Espinoza. Specialty in Obstetrics and Gynaecology, Pontificia Catholic University of Ecuador. Obstetrics and Gynaecology Treating Physician, El Puyo Basic Hospital. Puyo Ecuador. ORCID:https://orcid.org/0000-0002-3036-3254 Luis Ramiro Hidalgo Yánez. Doctor in Medicine and Surgery, Specialty in Obstetrics and Gynaecology Central University of Ecuador. Attending Physician of Obstetrics and Gynaecology, Hospital Carlos Andrade Marín. Quito - Ecuador. ORCID: https://orcid.org/0000-0001-9736-5783María Lucila Carrasco Guerra, Doctor of Medicine and Surgery, Medical or Clinical-Health Pathologist. Professor, Faculty of Medicine PUCE, Quito - Ecuador. Quito, Ecuador. ORCID: https://orcid.org/0000-0002-1552-8532Lautaro Santiago Chávez Iza, Doctor of Medicine and Surgery, Specialty in Obstetrics and Gynaecology, Central University of Ecuador. Attending Physician of Obstetrics and Gynaecology, Hospital Carlos Andrade Marín. Quito, Ecuador. ORCID: https://orcid.org/0000-0002-7506-4215 


\section{Availability of data and materials}

Free and limited use of physical and virtual bibliographic resources were used. The database was created based on the statistics of the High Obstetric Risk Center of the Carlos Andrade Marín Specialty Hospital, maintaining the confidentiality of data. Collected documents are available upon request to the main author.

\section{Ethics committee approval and consent to participation}

The study was approved in act \#010 on September 19, 2019; by the Human Research and Ethics Committee/Carlos Andrade Marín Specialty Hospital (CEISH / HECAM).

\section{Consent for publication}

Pending12. AcknowledgmentsSpecial thanks are given to the Department of Teaching and Research of the Carlos Andrade Marín Specialities Hospital, for providing the necessary permits and authorizations for the execution of the study, as well as the Maternal and Child and High Obstetric Risk Area for facilitating the search information from records doctors and nurses.

\section{Bibliographic references}

1. Vergara G. Protocolo Rotura de membranas Ovulares (RPM) [Internet]. 2009, 1:1. Available from:http://www.maternidadrafaelcalvo.gov.co/protocolos/PROTOCOLO_RPM.pdf

2. Schmitz T, Sentilhes L, Lorthe E, Gallot D, Madar H, Doret-Dion M, et al. Preterm premature rupture of the membranes: Guidelines for clinical practice from the French College of Gynaecologists and Obstetricians (CNGOF). European Journal of Obstetrics \& Gynecology and Reproductive Biology [Internet]. 2019; 1. doi: 10.1016/j.ejogrb.2019.02.021

3. Mercer, B. Preterm premature rupture of the membranes: current approaches to evaluation and management. Obstet Gynecol Clin North Am[Internet]. 2005;32(3):411-28. doi: 10.1016/j.ogc.2005.03.003

4. Kumar D, Moore R, Mercer B, Mansour M, Redline R, Moore J. The physiology of fetal membrane weakening and rupture: Insights gained from the determination of physical properties revisited. Placenta[Internet]. 2016:42:59-73. doi: 10.1016/j.placenta.2016.03.015.

5. Strauss J. Extracellular Matrix Dynamics and Fetal Membrane Rupture. Reproductive Sciences[Internet]. 2012:20(2), 140-153. doi: 10.1177/1933719111424454

6. Lugones M, Ramírez M. Rotura prematura de membranas, aspectos de interés para la atención primaria de salud. Revista Cubana de Medicina General Integral[Internet]. 2010:26(4), 682-693.

7. Chan G, Lee A, Baqui A, Tan J, Black R. Prevalence of early-onset neonatal infection among newborns of mothers with bacterial infection or colonization: a systematic review and meta-analysis. BMC Infec Dis[Internet]. 2015;7;15:118. doi: 10.1186/s12879-015-0813-3

8. Oppenheim J, Ruscetti F. Citoquinas. Capt 10. En: Parslow, T., Stite, D. Inmunología Básica y Clínica[Internet] 10ma. ed. México DF: Editorial El Manual Moderno. 2002,p.167.

9. Bryant-Greenwood G, Kern A, Yamamoto S, Sadowsky D, Novy M.. Relaxin and the human fetal membranes. Reproductive sciences [Internet]. 2007;14(8 Suppl):42-5. doi: 10.1177/1933719107310821.

10. Hasbun J, y Hasbun A. Infección y parto prematuro: Enlace epidemiológico y bioquímico. Rev Chil Infect [Internet]. 2000;17(1):7-17. Available from: https://scielo.conicyt.cl/pdf/rci/v17n1/art02.pdf

11. Romero R, Miranda J, Chaemsaithong P, Chaiworapongsa T, Kusanovic J, Dong Z, et al. Sterile and microbial-associated intra-amniotic inflammation in preterm prelabor rupture of membranes. The Journal of Maternal-Fetal \& Neonatal Medicine [Internet]. 2014;28(12), 1394-1409. doi: $10.3109 / 14767058.2014 .958463$

12. Rincón M, Magdaleno F, Sancha N, Omeñaca T, González A. Corioamnionitis histológica y morbimortalidad neonatal: aproximación al síndrome de respuesta inflamatoria fetal. Rev Chil Obstet Ginecol [Internet]. 2010;75(3):172-178. Available from: http://dx.doi.org/10.4067/S0717-75262010000300005

13. Saji F, Samejima Y, Kamiura S, Sawai K, Shimoya K, Kimura T. Cytokine production in chorioamnionitis. J Reprod Immunol [Internet]. 2000;47(2):185-96. Available from: https://www.ncbi.nlm.nih.gov/pubmed/10924750 
14. Muglia L, Katz M. The Enigma of Spontaneous Preterm Birth. New England Journal of Medicine [Internet]. 2010;362(6), 529-535. doi: 10.1056/nejmra0904308

15. Thompson D, Huffman K, Kraus W, Kraus V. Critical Appraisal of Four IL-6 Immunoassays. PLoS ONE [Internet]. 2012;7(2), e30659. doi: 10.1371/journal.pone.0030659

16. Chinedu U, Ebenebe, Hesse F, Blohm M, Jung R, Kunzmann, et al. Diagnostic accuracy of interleukin6 for early-onset sepsis in preterm neonates. The Journal of Maternal-Fetal \& Neonatal Medicine [Internet]. 2019;1-201. doi: 10.1080/14767058.2019.1606194

17. Romero J, Álvarez G, Ramos J. Manejo de Ruptura Prematura de Membranas Pretérmino. Rev Colegio Mexicano de Especialistas en Ginecología y Obstetricia [Internet]. 2010;175 - 193. Available from:http://www.comego.org.mx/GPC_TextoCompleto/7Manejo\%20de\%20ruptura\%20prematura\%20de\%20membranas\%20pretermino.pdf

18. Engle W, Kominiarek M. Late preterm infants, early term infants, and timing of elective deliveries. Clinics in Perinatology [Internet]. 2008;35(2):325-41. doi: 10.1016/j.clp.2008.03.003

19. Engle W, Tomashek K, Wallman C. Late preterm infants: a population at risk. Pediatrics [Internet]. 2007;120(6):1390-401. doi: 10.1542/peds.2007-2952

20. Van der Heyden J. Preterm prelabor rupture of membranes: different gestational ages, different problems. Doctoral Thesis. Maastricht University[Internet]. Netherlands. 2014. Available from: https://cris.maastrichtuniversity.nl/portal/files/1321295/guid-4cb916da-43f5-40e3-ba3d1a8d2e001b0f-ASSET3.0

21. Sae-Lin P, Wanitpongpan P. Incidence and risk factors of preterm premature rupture of membranes in singleton pregnancies at Siriraj Hospital. Journal of Obstetrics and Gynaecology[Internet]. 2018:1-5. doi: $10.1111 /$ jog. 13886

22. Gyamfi B, Thom E, Blackwell S, Jain L. Antenatal batamethasone for women at risk for late preterm delivery. N Engl J Med[Internet]. 2016:7;374(14):1311-20. doi: 10.1056/NEJMoa1516783.

23. American College of Obstetricians and Gynecologists. Prelabor Rupture of Membranes (Practice Bulletin No. 188). Obstetrics \& Gynecology[Internet]. 2018:131(1), e1-e14. doi: 10.1097/aog.0000000000002455

24. Bond D, Middleton P, Levett K.M, Van der Ham D, Crowther C, Buchanan S, Morris J. Planned early birth versus expectant management for women with preterm prelabour rupture of membranes prior to 37 weeks' gestation for improving pregnancy outcome. Cochrane Database of Systematic Reviews[Internet]. 2017:3;(3):CD004735. DOI: 10.1002/14651858.CD004735.pub4

25. Seong H, Lee S, Kang J, Romero R, Yoon B. The frequency of microbial invasion of the amniotic cavity and histologic chorioamnionitis in women at term with intact membranes in the presence or absence of labor. American Journal of Obstetrics and Gynecology[Internet]. 2008:199(4), 375.e1-375.e5. doi: 10.1016/j.ajog.2008.06.040

26. Dulay A, Buhimschi I, Zhao G, Bahtiyar M, Thung S, Cackovic M, Buhimschi C. Compartmentalization of acute phase reactants Interleukin-6, C-Reactive Protein and Procalcitonin as biomarkers of intra-amniotic infection and chorioamnionitis. Cytokine[Internet]. 2015:76(2), 236-243. doi: 10.1016/j.cyto.2015.04.014

27. Popowski T, Goffinet F, Batteux F, Maillard F, Kayem G. Prediction de l'infection maternofœtale en cas de rupture prématurée des membranes par les marqueurs sériques maternels. Gynécologie Obstétrique \& Fertilité[Internet]. 2011:39(5), 302-308. doi: 10.1016/j.gyobfe.2010.11.006

28. Federación Argentina de Sociedades de Ginecología y Obstetricia, Rotura Prematura De Membranas (Consenso XXXIII) [Internet]. 2018. Available from: http://www.fasgo.org.ar/archivos/consensos/Consenso_FASGO_2018_Rotura_prematura_de_membranas.pdf

29. Royal College of Obstetricians and Gynaecologists. Care of Women Presenting with Suspected Preterm Prelabour Rupture of Membranes. Green-top Guideline No. XX[Internet]. London. 2018. Available from: rcog.org.uk/GTG99

30. Quist J, de Ruigh A, Seidler A, Van der Ham D, Willekes C, Berghella V, et al. Immediate Delivery Compared With Expectant Management in Late Preterm Prelabor Rupture of Membranes: 
An Individual Participant Data Meta-analysis. Obstet Gynecol[Internet]. 2018:131(2):269-279. doi: 10.1097/AOG.0000000000002447

31. Morris J, Roberts C, Bowen J, Patterson J, Bond D, Algert, C, et al. Immediate delivery compared with expectant management after preterm pre-labour rupture of the membranes close to term (PPROMT trial): a randomised controlled trial. The Lancet[Internet]. 2016:387(10017), 444-452. doi:10.1016/s01406736(15)00724-2

32. Van der Ham D, Van der Heyden J, Opmeer B, Mulder A, Moonen R, et al. Management of latepreterm premature rupture of membranes: the PPROMEXIL-2 trial. Am J Obstet Gynecol[Internet]. 2012a:207(4):276.e1-10. doi: 10.1016/j.ajog.2012.07.024.

33. Van der Ham D, Vijgen S, Nijhuis J, Ban B, Opmeer B, Mulder A, et al. Induction of labor versus expectant management in women with preterm prelabor rupture of membranes between 34 and 37 weeks: a randomized controlled trial. PLoS Med[Internet]. 2012b:9(4):e1001208. doi: 10.1371/journal.pmed.1001208.

34. Téllez D, Ramírez S, Parada N, Fernández J. Inducción del parto versus menejo expectante en ruptura prematura de membranas pretérmino: revisión sistemática y metanálisis. Rev Univ Ind Santander Salud[Internet]. 2017:49(1):45-55. doi: http://dx.doi.org/10.18273/revsal.v49n1-2017005

35. Saccone G, Berghella V. Antenatal corticosteroids for maturity of term or near term fetuses: systematic review and meta-analysis of randomized controlled trials. BMJ (Clinical research ed.) [Internet]. 2016:355, i5044. doi: 10.1136/bmj.i5044

36. Meller C, Carducci M, Ceriani J, Otaño L. Ruptura prematura de membranas en nacimientos de pretérmino. Arch Argent Pediatr[Internet]. 2018:116(4):e575-e581. Available from: http://dx.doi.org/10.5546/aap.2018.e575

37. Gasque J. Revisión y actualización de enterocolitis necrosante. Revista Mexicana de Pediatría[Internet]. 2015:82(5):175-185. Available from: https://pdfs.semanticscholar.org/047d/cc9446b730f6a13daac86c12f541fe2a66ff.pdf

38. Rodríguez I, de la O-Cavazos M, Martínez A, Cadena I, Flores K. Sensitivity of histological chorioaminionitis and premature rupture of membranes for neonatal sepsis and its risk factors. Medicina Universitaria[Internet]. 2016:18(70), 10-15. doi: 10.1016/j.rmu.2016.01.001

39. Gisslen T, Alvarez M, Wells C, Soo M, Lambers D, Knox C, et al. Fetal inflammation associated with minimal acute morbidity in moderate/late preterm infants. Archives of Disease in Childhood - Fetal and Neonatal Edition[Internet]. 2016:101(6), F513-F519. doi: 10.1136/archdischild-2015-308518

Tables.

Table 1. Clinical characteristics of the patients treated for premature rupture of membranes at the Carlos Andrade Marín Hospital, between 2016 and July 2019

\begin{tabular}{llc}
\hline Variable & Management & M \\
& Expectant & Ex \\
& N & M \\
Membrane Rupture Time & Membrane Rupture Time & 55. \\
Less than 24 hours & 57 & 10. \\
Greater than 24 hours & 11 & 22. \\
From 2 to 6 days & 2.3 & 11. \\
More than 7 days & 12 & $\mathbf{P u}$ \\
Pulmonary Maturation with Corticosteroids & Pulmonary Maturation with Corticosteroids & 54. \\
One batch & 56 & 3.9. \\
Two batches & 4 & 41. \\
Not applied & 43 & Sig \\
Signs of Intrauterine Infection & Signs of Intrauterine Infection & 100 \\
No infection signs & 103 &
\end{tabular}




\begin{tabular}{llc}
\hline Variable & Management & M. \\
\hline Maternal infection due to elevated serum markers & Maternal infection due to elevated serum markers & $\mathbf{M}$ \\
Yes & 16 & 15. \\
Not & 87 & 84. \\
Antibiotic Scheme & Antibiotic Scheme & $\mathbf{A n}$ \\
No use antibiotic terapy & 21 & 20. \\
Incomplete scheme & 73 & 70. \\
Complete scheme & 9 & 8.7 \\
New Scheme & 0 & 0.0 \\
Delivery Form & Delivery Form & De \\
Normal delivery & 77 & 74. \\
Caesarean section & 26 & 25. \\
Caesarean Reason & Caesarean Reason & Ca \\
Previous placenta & 0 & 0.0 \\
Dilation Dystocia & 2 & 7.7 \\
Oligoamnios & 4 & 15.8 \\
Cephalo-pelvic disproportion & 1 & 3.8 \\
Induction Failed & 0 & 0.0 \\
Fetal well-being compromise & 2 & 7.7 \\
Previous caesarean section & 11 & 42. \\
Pelvian & 5 & 19. \\
Keratoconus maternal & 1 & 3.8 \\
$*$ Pearson's Chi Square & $*$ Pearson's Chi Square & I. \\
\hline
\end{tabular}

Source: 2019 Research Data

Prepared by: Jácome et al. (2019)

Table 2. Analysis of inflammatory biomarkers and hematological parameters in patients with premature rupture of membranes and apparent maternal infection (determined by leucocytes over 15,000 cells $/ \mathrm{mm} 3$ and Interleukin-6, greater than $14 \mathrm{pg} / \mathrm{mL}$ )

\begin{tabular}{|c|c|}
\hline Hematological / Biomarker Values & Maternal infection \\
\hline Leucocytes (cells x 103/mm ${ }^{3}$ ) & $\begin{array}{l}\text { Yes } \\
\text { Not }\end{array}$ \\
\hline Neutrophils (\%) & $\begin{array}{l}\text { Yes } \\
\text { Not }\end{array}$ \\
\hline Procalcitonin (ng/mL) & $\begin{array}{l}\text { Yes } \\
\text { Not }\end{array}$ \\
\hline C Reactive Protein (mg/dL) & $\begin{array}{l}\text { Yes } \\
\text { Not }\end{array}$ \\
\hline Interleukin $6(\mathrm{pg} / \mathrm{mL})$ & $\begin{array}{l}\text { Yes } \\
\text { Not }\end{array}$ \\
\hline * SD: Standard Deviation, ${ }^{* *}$ Student's $t$ for independent samples; ${ }^{* * *} F$ : Levene's test & ${ }^{*}$ SD: Standard Deviation, ${ }^{* *}$ St \\
\hline
\end{tabular}

Source: 2019 Research Data

Prepared by: Jácome et al. (2019)

Table 3. Clinical characteristics of neonates by mothers with premature rupture of membra- 
nes; underactive or expectant management at the Carlos Andrade Marín Specialty Hospital between 2016 and July 2019

\begin{tabular}{|c|c|c|}
\hline Variable & Management & Management \\
\hline & Expectant & Expectant \\
\hline & $\mathbf{N}$ & $\%$ \\
\hline Newborn Sex & Newborn Sex & Newborn Sex \\
\hline Male & 59 & $57.3 \%$ \\
\hline Female & 44 & $42.7 \%$ \\
\hline Newborn Weight & Newborn Weight & Newborn Weight \\
\hline Less than 2500 grams & 55 & $53.4 \%$ \\
\hline Greater than 2500 grams & 48 & $46.6 \%$ \\
\hline Apgar (1 min $)$ & Apgar (1 min) & Apgar (1 min) \\
\hline 0 to 3 points & 0 & $0.0 \%$ \\
\hline From 4 to 6 points & 0 & $0.0 \%$ \\
\hline 7 to 10 points & 103 & $100.0 \%$ \\
\hline Apgar (5 min) & Apgar (5 min) & Apgar (5 min) \\
\hline 0 to 3 points & 0 & $0.0 \%$ \\
\hline From 4 to 6 points & 0 & $0.0 \%$ \\
\hline 7 to 10 points & 103 & $100.0 \%$ \\
\hline Neonate Hospitalization Time & Neonate Hospitalization Time & Neonate Hospitalization Tim \\
\hline Normal (24 to 48 hours) & 42 & $40.8 \%$ \\
\hline Prolonged ( $>48$ hours) & 61 & $59.2 \%$ \\
\hline Reason for prolonged hospitalization & Reason for prolonged hospitalization & Reason for prolonged hospita \\
\hline Antibiotic therapy & 5 & $7.9 \%$ \\
\hline Enteritis - Rotavirus & 0 & $0.0 \%$ \\
\hline Infection Study & 25 & $39.7 \%$ \\
\hline Hyperbilirubinemia & 14 & $22.2 \%$ \\
\hline Neonatal Poor Adaptation & 2 & $3.2 \%$ \\
\hline Polycythemia & 2 & $3.2 \%$ \\
\hline Respiratory Distress Syndrome & 15 & $23.8 \%$ \\
\hline * Pearson's Chi Square & *Pearson's Chi Square & * Pearson's Chi Square \\
\hline
\end{tabular}

Source: 2019 Research Data

By: Jácome et al. (2019)

Table 4. Complications in newborns of mothers with premature rupture of membranes under active and expectant treatment at the Carlos Andrade Marín Specialty Hospital between 2016 and July 2019

\begin{tabular}{lll}
\hline Variable & Management & Management \\
\hline & Expectant & Expectant \\
& N & \% \\
Clinical Signs of Neonatal Infection & Clinical Signs of Neonatal Infection & Clinical Signs of Neonatal In \\
Yes & 3 & $2.9 \%$ \\
Not & 100 & $97.1 \%$ \\
Blood Culture Results & Blood Culture Results & Blood Culture Results \\
Positive & 2 & $1.9 \%$ \\
Negative & 35 & $34.0 \%$ \\
Unrealized & 66 & $64.1 \%$
\end{tabular}




\begin{tabular}{lll}
\hline Variable & Management & Management \\
\hline Neonatal infection & Neonatal infection & Neonatal infection \\
Yes & 15 & $14.6 \%$ \\
Not & 88 & $85.4 \%$ \\
Antibiotic Treatment in the Neonate & Antibiotic Treatment in the Neonate & Antibiotic Treatment in the \\
No scheme applied & 60 & $58.3 \%$ \\
Incomplete antibiotic scheme & 32 & $31.1 \%$ \\
Complete antibiotic scheme & 11 & $10.7 \%$ \\
New antibiotic scheme & 0 & $0.0 \%$ \\
Neonatal Ventilatory Support & Neonatal Ventilatory Support & Neonatal Ventilatory Suppor \\
None & 78 & $75.7 \%$ \\
Nasal cannula & 6 & $5.8 \%$ \\
Hood & 4 & $3.9 \%$ \\
CPAP & 15 & $14.6 \%$ \\
Invasive Mechanical Ventilation & 0 & $0.0 \%$ \\
Necrotizing Enterocolitis & Necrotizing Enterocolitis & Necrotizing Enterocolitis \\
Yes & 1 & $1.0 \%$ \\
Not & 102 & $99.0 \%$ \\
Neonate Hospitalization Time & Neonate Hospitalization Time & Neonate Hospitalization Tim \\
(Normal) < 48 hours & 42 & $40.8 \%$ \\
(Prolonged) > 48 hours & 61 & $59.2 \%$ \\
Prolonged Hospitalization Causes & Prolonged Hospitalization Causes & Prolonged Hospitalization Ca \\
Antibiotic therapy & 4 & $6.1 \%$ \\
Enteritis - Rotavirus & 1 & $1.5 \%$ \\
Infection Study & 17 & $25.8 \%$ \\
Hyperbilirubinemia & 17 & $25.8 \%$ \\
Neonatal Poor Adaptation & 4 & $6.1 \%$ \\
Polycythemia & 0 & $0.0 \%$ \\
Respiratory Distress Syndrome & 2.3 & $34.8 \%$ \\
Neonatal death & Neonatal death & Neonatal death \\
Yes & 0 & $0.0 \%$ \\
Not & 103 & $100.0 \%$ \\
Pearson's Chi Square & $*$ Pearson's Chi Square & $*$ Pearson's Chi Square \\
\hline & & \\
& &
\end{tabular}

Source: 2019 Research Data

Prepared by: Jácome et al. (2019)

Table 5. Relationship between gestational age and the presence of complications in newborns of mothers with premature rupture of membranes at the Carlos Andrade Marín Specialty Hospital, between 2016 and July 2019

\begin{tabular}{|c|c|c|}
\hline Complications & Gestational age in days & Gestational age in days \\
\hline & $\begin{array}{l}238-245 \\
N\end{array}$ & $\begin{array}{l}238-245 \\
\%\end{array}$ \\
\hline Neonatal infection & Neonatal infection & Neonatal infection \\
\hline Yes & 10 & $15.6 \%$ \\
\hline Not & 54 & $84.4 \%$ \\
\hline Neonatal Ventilatory Support & Neonatal Ventilatory Support & Neonatal Ventilatory Supp \\
\hline None & 37 & $57.8 \%$ \\
\hline Nasal cannula & 4 & $6.3 \%$ \\
\hline
\end{tabular}




\begin{tabular}{lll}
\hline Complications & Gestational age in days & Gestational age in days \\
\hline Hood & 5 & $7.8 \%$ \\
CPAP & 18 & $28.1 \%$ \\
Invasive Mechanical Ventilation & 0 & $0.0 \%$ \\
Diagnosis of Necrotizing Enterocolitis & Diagnosis of Necrotizing Enterocolitis & Diagnosis of Necrotizing Er \\
Yes & 1 & $1.6 \%$ \\
Not & 63 & $98.4 \%$ \\
Neonate Hospitalization Time & Neonate Hospitalization Time & Neonate Hospitalization Ti \\
(Normal) < 48 hours & 15 & $23.44 \%$ \\
(Prolonged) > 48 hours & 49 & $76.56 \%$ \\
Causes of Prolonged Hospitalization & Causes of Prolonged Hospitalization & Causes of Prolonged Hospi \\
Antibiotic therapy & 4 & $8.16 \%$ \\
Enteritis - Rotavirus & 0 & $0.00 \%$ \\
Infection Study & 17 & $34.69 \%$ \\
Hyperbilirubinemia & 8 & $16.33 \%$ \\
Neonatal Poor Adaptation & 0 & $0.00 \%$ \\
Polycythemia & 1 & $2.04 \%$ \\
Respiratory Distress Syndrome & 19 & $38.78 \%$ \\
$*$ Pearson's Chi Square & $*$ Pearson's Chi Square & $*$ Pearson's Chi Square \\
\hline
\end{tabular}

Source: 2019 Research Data

Prepared by: Jácome et al. (2019)

Table 6 . Relationship of pulmonary maturation with corticosteroids and the presence of respiratory distress syndrome in newborns of mothers with premature rupture of membranes at the Carlos Andrade Marín Specialty Hospital, between 2016 and July 2019

\begin{tabular}{lll}
\hline Complication & Expectant Management / Maturation & Expectant Management / Matura \\
& Not & Not \\
& $\mathbf{n}$ & $\%$ \\
Respiratory Distress Syndrome & Respiratory Distress Syndrome & Respiratory Distress Syndrome \\
Yes & 21 & $35.0 \%$ \\
Not & 39 & $65.0 \%$ \\
Neonatal Ventilatory Support & Neonatal Ventilatory Support & Neonatal Ventilatory Support \\
None & 39 & $65.0 \%$ \\
Nasal cannula & 3 & $5.0 \%$ \\
Hood & 3 & $5.0 \%$ \\
CPAP & 15 & $25.0 \%$ \\
Invasive Mechanical Ventilation & 0 & $0.0 \%$ \\
* Pearson's Chi Square & $*$ Pearson's Chi Square & $*$ Pearson's Chi Square \\
\hline
\end{tabular}

Source: 2019 Research Data

Prepared by: Jácome et al. (2019)

Table 7. Analysis of the risk of maternal and neonatal complications based on the treatment applied to patients for premature membrane rupture at the Carlos Andrade Marín Specialty Hospital, between 2016 and July 2019 


\begin{tabular}{lc}
\hline & Expectant Management \\
\hline Related Factor & RR * \\
& Maternal \\
Maternal & 1,324 \\
Maternal infection & Neonatal \\
Neonatal & 0.909 \\
Sepsis & 0.993 \\
Respiratory Distress Syndrome & 0.673 \\
Necrotizing enterocolitis & 0.891 \\
Prolonged Hospitalization & 1 \\
Death in the NICU & \\
RR: Relative Risk, ** CI: Confidence Interval, *** NICU: Neonatal Intensive Care Unit RR: Relative Risk, ** CI: C & $*$ \\
\hline
\end{tabular}

Source: 2019 Research Data

Prepared by: Jácome et al. (2019) 